\title{
Building Blocks for Volume-Oriented Changeability in Personnel Cost Structure of Manufacturing Companies
}

\author{
Manuel Rippel*, Jost-Wolfram Budde, Felix Friemann, and Paul Schönsleben \\ ETH Zurich, BWI Center for Industrial Management, Zurich, Switzerland \\ mrippel@ethz.ch
}

\begin{abstract}
Volatilities in global markets lead to rising importance of volumeoriented changeability ( $\mathrm{VoC})$ in the manufacturing industry. If the production demand is fluctuating, manufacturing companies often struggle to adapt their overhead costs, which are causing high variances in unit costs. Personnel is a main cost driver in overhead cost structure, in particular in high-wage countries. Therefore, this paper conceptualizes building blocks and analyzes impact relations for configuring $\mathrm{VoC}$ in personnel cost structure in production plants.
\end{abstract}

Keywords: Flexibility, Volatility, Volume-oriented Changeability, Personnel.

\section{Introduction}

Nowadays, companies are facing uncertainty in global markets as an omnipresent condition. For that reason, Wiendahl et al. introduced the concept of changeability as a system's potential to conduct technological, logistical, organizational and personnel changes beyond the available system-inherent flexibility corridors by means of an acceptable effort [1]. In particular manufacturing companies have to configure their capacities and capabilities in their production plant under the uncertainties of high volatility of order volumes [2]. Therefore, they are forced to find ways to economically adapt their cost structure to the fluctuating production volume, since manufacturing costs are highly sensitive due to fixed cost component [3]. Rippel et al. introduced the concept of "volume-oriented changeability" (VoC) focusing on the change dimension "volume", expand existing considerations of changeability to an socio-technical perspective and include indirect aspects in the plant environment [4]. This is particularly important, since around 50\% of employees are working in support processes and their cost structure mainly consists of fixed costs [5]. Interdependencies of instruments, numerous influencing factors and general conditions, such as restrictive labor legislations, limitations due to social appropriateness and compliance with corporate cultural values, complicate the configuration of $\mathrm{VoC}$ of personnel cost structure [6]. Thus, the objective of this paper is to conceptualize building blocks for $\mathrm{VoC}$ and analyze their impact relations in order to support plant management to preventively set-up a holistic package with ready-to-use instruments for adapting personnel capacity and influence associated personnel costs. 
The findings have been developed through literature studies and interviews with three manufacturing companies from two industries (automobiles \& parts, industrial goods \& services). In addition, insights and findings were embedded, which were gained within the design and implementation of $\mathrm{VoC}$ at four production plants of a case study company (construction \& materials, personal \& household goods).

The multitude of existing obstacles reveal the need to systematize categories as building blocks for enhancing transparency and facilitating a basic configuration. The following questions will be answered: (1) Which decisive categories of enablers and levers do exist? (2) Which main influencing variables and impact relations have to be considered? (3) How does the combination of the building blocks look like?

\section{Conceptualizing Building Blocks}

This section presents the findings of the conducted case studies by conceptualizing building blocks as aggregated categories of instruments and design elements (see Fig. 1). It is intended to cover the most relevant topics but not to be exhaustive. The formalization differs from classical considerations, since the decisive factor of the category scheme is the mechanism contributing to VoC. Some instruments have a direct influence on the fields of impact, whereas some others indirectly affect them. The building blocks can be distinguished in "Enablers", which comprise the prerequisites for the set-up and execution of instruments, and in "Levers", which systematize instruments according to their impact mechanism.

\subsection{Enablers}

The enabler "work organization" provides the framework for the working-timesystem, staffing levels, autonomous work groups as well as the organizational design of the system regarding structure and process organization. Depending on the design, the work organization itself provides flexibility potential or the requirements for the use of certain flexibility instruments. Thus the work organization can be seen as a condition or as an object of flexibility measures [7]. Work organization provides system-inherent capacity leeway by introducing employee-related instruments (e.g., job rotation, home office) and measures that increase the employability, which define the qualification for flexible workforce deployment with regard to shifting of capacities. Various measures of employability can be distinguished according to [8]. In addition to employee-related measures, such as improving workforce flexibility, career models and health promotion, there are also business-related measures, which focus on the change management style or changes in corporate culture and organizational structure. Besides, the work organization also facilitates instruments in the value chain (e.g., extended work bench) by reorganizing tasks for execution by third parties and establishing interfaces with external partners.

The enabler "arrangement" includes formalities related to the position, location and duration of working-time. Within the design of internal arrangements (e.g., labor contracts, agreements with work councils) the possible use of flexibility measures 
must be taken into account [9], e.g. scope of employment, periods of notice and contracts with for a limited period of time. Working-time flexibility can also be supported by clauses for additional or reduced working-time (e.g., employment leveling). The precise and transparent definition of rules and standards as well as trigger points and escalation levels for the activation of measures will enable mutual understanding and acceptance of both employees and employer. Employees benefit from minimized uncertainty with regards to the further approach. The employer benefits from a prealigned and prepared set of measures, which significantly increases the scope and speed of action in case of unforeseen demand fluctuations.

The enabler "time accounts" consists of working-time accounts, which are used to decouple contractual working hours and actual operated work. Working-time accounts are not independent models, but are often required as a basis for using working-time models. The combination of different types (e.g., work-time account, saving account, life-work-time account), their individual purpose and their interaction enable the implementation of various instruments by means of providing a reserve of work hours as "breathing volume". Thereby, position and duration of operated work can be adapted, when the demand differs from the contractual work time as regular baseline.

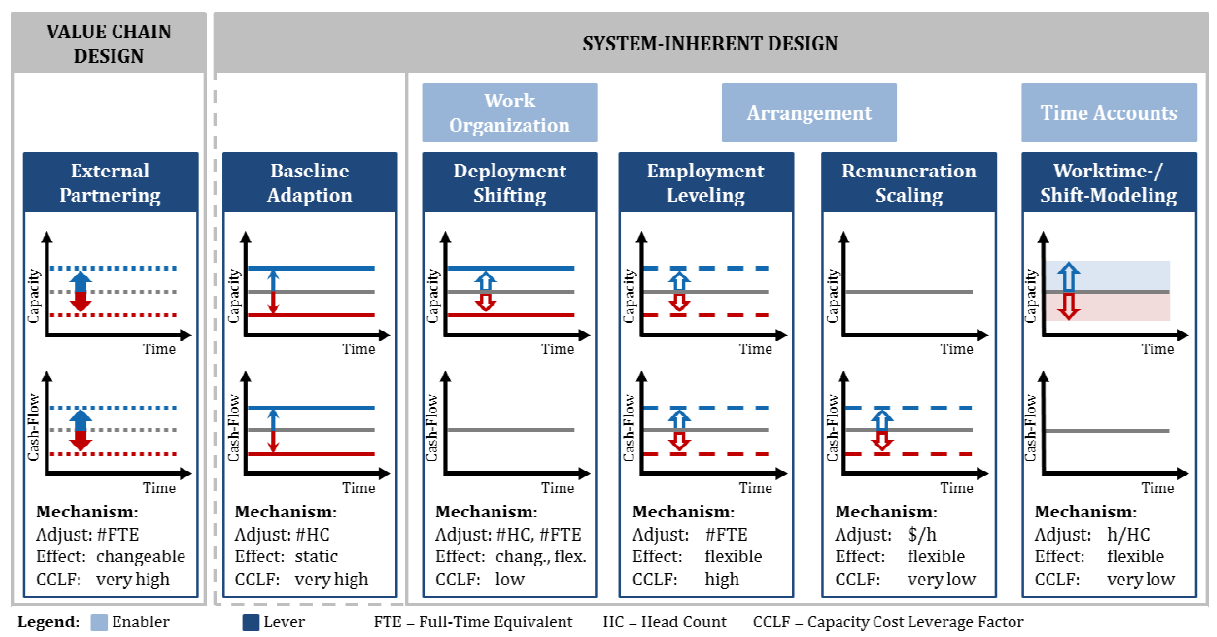

Fig. 1. Enablers and levers within value chain and system-inherent design

\subsection{Levers}

The lever "worktime / shift-modeling" consists of flexible working-time models (e.g., trust-based work time, flextime) and options to adapt the shift-model (e.g., shortening/extensions, additional shifts, holidays and weekends). Instruments of this block change the duration and the position of working-time.

The lever "remuneration scaling" defines ways of remuneration contributing to VoC. Roughly they can be divided into fixed salary, bonuses or flexible wage components. They must include a demand-oriented component instead or in addition to the common performance-oriented components. 
The lever "employment leveling" comprises instruments to adapt the contractual working hours and thereby the capacity baseline, which couples the personnel expenditures (both direct and indirect labor costs), operated work and capacity demand. For example, a contractually regulated time-corridor defines which working-time must be fulfilled by the employee in case of deviations from the contractual workinghours. Thereby, the corridor can be used to extend or shorten working-time and time used within the corridor can be accounted on a working-time account. To provide a cash-effective capacity flexibility the accounting balance of the corridor can be determined with an effect on the remuneration. In that case a debt on the working-time account means a reduction of remuneration for the employee. The instrument "basis adjustment" can provide further system-inherent potential by means of an adaptation of working-time-related contractual components. It describes the possibility to adjust the time-corridor or the contractual working-hours after a certain contractual period.

The lever of "deployment shifting" consists of measures for flexible workforce deployment. The area of application of the flexible employee may be beyond department employee pools, plant-wide, company-wide or beyond the corporate boundaries [10]. Utilization deviations between working-groups or production units can be balanced by horizontal shifting of trained employees. Furthermore, multi-skilled employees from indirect functions can extend production capacity. In particular a combination with temporary workers provides impact potential. For instance, in case of a decline of production output, the capacity of temporary workers in production units can be disproportionately reduced. The gap can be filled by vertical shifting of employees from indirect areas. Features to be determined are the duration of use which can be predetermined or demand-oriented. Features that describe capacitive impacts are the need for training the employee or the employee's productivity to perform nonspecialist tasks. Apart from that, remuneration models should be adapted according to the qualification requirement of the task or to working-time duration.

The lever "baseline adaption" is differentiated from other system-inherent building blocks, since it determines the baseline of internal personnel resources. An increase (or decrease) implies that new resources are brought inside the system from the outside (and vice versa). Therefore, these instruments are indirectly considered as system-inherent. Furthermore, the changes of internal capacity and associated cost level are relatively static (e.g., hiring, dismissal) and partially non-reversible (e.g., early retirement). The impact of the instruments is discrete and fairly long-term, whereby incremental and continuous adaptations prove to be difficult.

The lever "external partnering" contains options within the value chain to cover capacity demands. The design of the contract is crucial for utilizing external partnering as a $\mathrm{VoC}$ instrument, since the type of commitment allows adapting both capacity and associated payments: Firstly, the provision of service or capacities can be fixed by contract or aligned to the current demand. Thereby, the VoC potential depends, among others, on the period of notice, guaranteed purchase quantities, degree of risk participation by means of compensation payments in case of shortfall of minimum quantities [3] or the option of recurring basis adaptation of agreed services during the contract period in flexible intervals. Secondly, the cost model defines if the service should be considered as fixed or variable cost. In case of lump-sum contracts the fixed cost lead to a high operating leverage. This causes a deterioration of profitability in 
periods of demand decline [3]. If the payments depend on the amount of delivered services, the cost structure varies and is in line with the demand. Thirdly, it is important for a demand-oriented dimensioning of the service to compare the performance (e.g., productivity) of external capacity with internal resources.

\section{$3 \quad$ Analyzing Impact Relations}

The building blocks have impacts in technical, financial and social dimensions. In the following the individual, basic leverage effects on the most relevant fields of impact are displayed (see Fig. 2). Nevertheless, their existence, direction and extent depend on influencing variables, which are introduced initially.

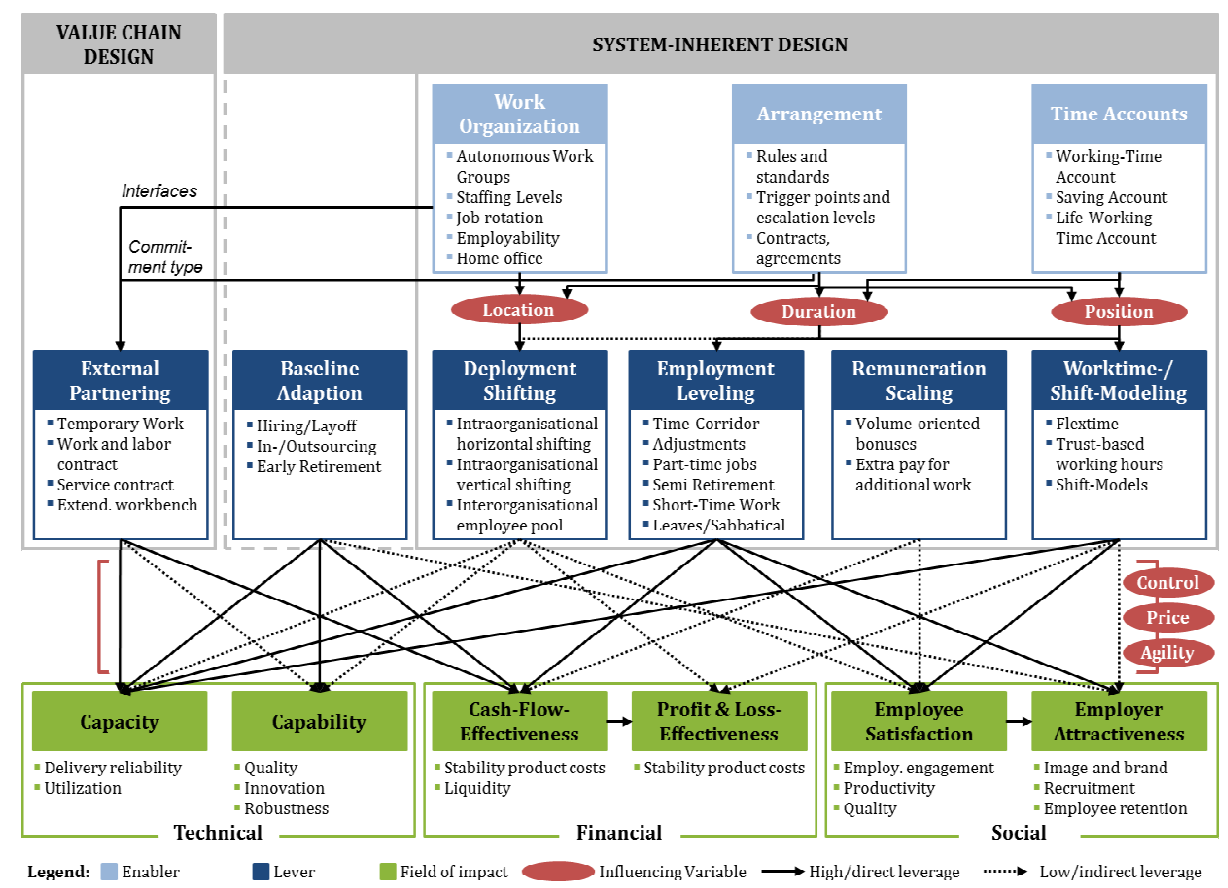

Fig. 2. Building blocks, influencing variables and fields of impact

\subsection{Influencing Variables}

The influential variable "control" has a crucial role in the process of configuring the building blocks, since the $\mathrm{VoC}$ potential of each measure strongly depends which stakeholder has which rights related to each measure. For example, the VoC potential of an employee-controlled working-time account significantly differs from an employer-controlled working-time account. The rights can be distinguished in decision and disposition right. The decision right determines a party's right to decide whether a measure is performed or not. The scope and timing of the measure are determined by 
the party with the disposition right $[11,12]$. These rights can be hold by the employee, employer or both. "Price" involves the fact, that most instruments entail costs, since the risk of underutilized capacities is allocated to another party (e.g. employees or external partners). This party will demand a risk premium [4]. "Agility" underlines the importance of the temporal dimension, e.g. the required time to implement or to exploit the potential of a measure. The variable "duration" describes the duration of working-time in a given period and "position" comprises, when the work is conducted during a period. "Location" determines, where the task is performed, e.g. at another production unit or another plant.

\subsection{Fields of Impact}

The primary field of impact is personnel "capacity", which must be provided in the necessary quantity at the right time at the right place with the required capability. Thereby, the building blocks are contributing to delivery reliability and high utilization. The field "capability" is considered, since instruments can affect the organization's know-how, which is indirectly related to the company's performance in the long-term. The financial implication of the building blocks requires to distinguish "Profit \& Loss-Effectiveness" (P\&L) and "Cash-flow-Effectiveness". The P\&LEffectiveness contributes to keep the variances of product cost stable despite of demand fluctuations. Nevertheless, the Cash-Flow-Effectiveness is of major relevance, since it also affects the cash-flow. The difference can be illustrated by looking at the lever "Worktime / Shift-Modeling": The required capacity can be provided by adapting the amount of working hours. Thereby, the performed working hours differ from the regular working hours, which are stated in the contract. The deviation between performed and contractual working hours is recorded in a time account. Furthermore, the performed working hours are solely booked as personnel costs in the Profit- $\&$ Loss statement (P\&L-effective). Nevertheless, the employees receive the same payments each month according to the contractual working hours and independent from the performed working hours, respectively the capacity requirements. This implies that the cash-flow of the organization remains unaffected, which could cause liquidity shortages in a long-lasting crisis. Particular instruments leverage the field "employee satisfaction", if they have participation options, e.g. decision and disposition rights with regards to duration and position of work-time or adjustments of employment level depending on the individual phase of life. This results in higher motivation, which can also increase the quality or productivity of their work [13]. The company can also enhance its "employer attractiveness" on the job market, if employee's needs are addressed in the design of the work-time system [14].

\section{Combining Impact Potentials}

Changeability in working-time-systems is usually determined by the possibility of a structural adaption to changing requirements [15]. The VoC potential in the scheme of the building blocks is exemplarily illustrated in Fig. 3 The combination of various building blocks results in increasing flexibility corridors and VoC potentials. It 
becomes apparent, that some instruments just enhance the potential with regards to capacity but do not affect the ability to adapt the corresponding cash-flow. This is crucial important for maximizing the ability to handle volume fluctuations economically. System-inherent instruments with an impact on cash-flow (e.g., employment leveling) are demanding a lot from employees, since their salaries are adapted. Instruments within external partnering enable to avoid the impact for internal employees. It is social reasonable to set up this potential in growth phases.

The concept provides guidance for practitioners within $\mathrm{VoC}$ in personnel capacities. A holistic package of ready-to-use instruments can be preventively implemented to increase the potential to act in volatile business environments. Thereby, responsiveness, speed and commensurability of actions as well as the transparency of associated impacts for both management and employees can be increased significantly. The benefits consist in the capability to adapt the personnel cost structure and associated multi-dimensional key performance indicators. The economic implications can be derived from the comparison of costs and benefits of the instruments.

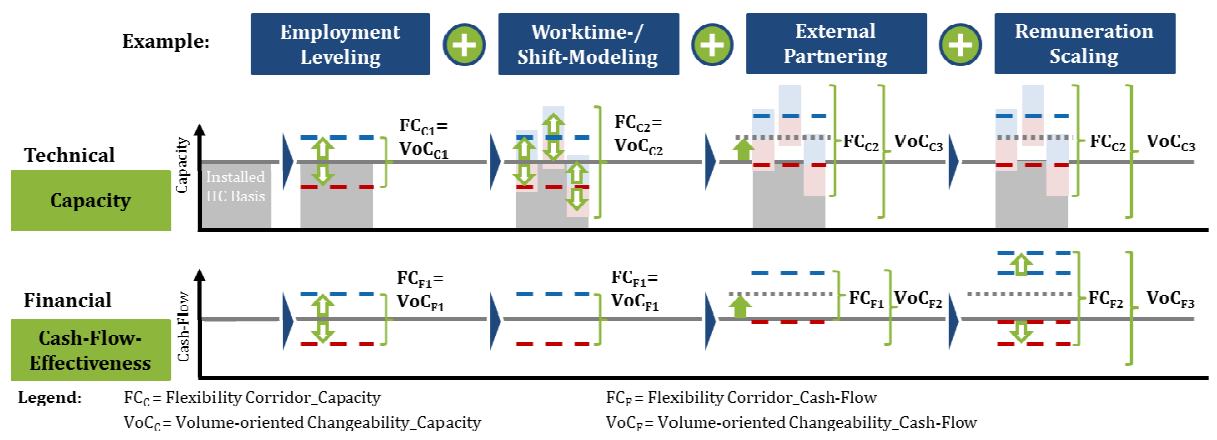

Fig. 3. Exemplary combination of impact potentials from a technical and financial perspective

\section{Conclusion and Outlook}

The building blocks provide companies a comprehensive overview of relevant design fields, which should be considered to use leverage effects. The concept gives direction to conduct a first basic configuration on strategic level. This creates the foundation for further dimensioning and detailing. The novelty lies in the provided transparency with regards to the scope, categories and impact relations of the various existing instruments. Decision-makers are enabled to consider multi-dimensional implications. Additionally, the distinction between P\&L-effective and cash-floweffective impact implies an aspiration level with regards to changeability, which is beyond the common focus in existing literature.

Limitations exist in the limited number of selected decisive influencing factors and fields of impact in order to make the scheme applicable for practical use on strategic level. In a next step, a simulation model is required for dimensioning the building 
blocks. The simulation of the working-time-system's behavior regarding the impact and interdependencies of the building blocks can be used to display fundamental effects on capacity and costs before starting implementation of VoC in the company. In addition, an appropriate and reasonable balance between technical, financial and in particular social aspects has to be considered.

\section{References}

1. Wiendahl, H.-P., ElMaraghy, H.A., Nyhuis, P., Zäh, M.F., Wiendahl, H.-H., Duffie, N., Brieke, M.: Changeable Manufacturing - Classification, Design and Operation. CIRP Annals - Manufacturing Technology 56(2), 783-809 (2007)

2. Raturi, A.S., Jack, E.P.: Creating a volume-flexible firm. Business Horizons 47(6), 69-78 (2004)

3. Wildemann, H.: Fixkostenmanagement - Leitfaden zur Anpassung von Kostenstrukturen an volatile Märkte. TCW Transfer-Centrum, München (2009)

4. Rippel, M., Lübkemann, J., Nyhuis, P., Schönsleben, P.: Profiling as a means of implementing volume-oriented changeability in the context of strategic production management. CIRP Annals - Manufacturing Technology, 8-11 (2014)

5. Remer, D.: Einführen der Prozesskostenrechnung: Grundlagen, Methodik, Einführung und Anwendung der verursachungsgerechten Gemeinkostenzurechnung. Schäffer-Poeschel, Stuttgart (2005)

6. Letmathe, P., Petersen, L., Schweitzer, M.: Capacity management under uncertainty with inter-process, intra-process and demand interdependencies in high-flexibility environments. OR Spectrum 35(1), 191-219 (2012)

7. Nyhuis, P., Reinhart, G., Abele, E. (eds.): Wandlungsfähige Produktionssysteme - Heute die Industrie von morgen gestalten. PZH Verlag, Garbsen (2008)

8. Rump, J., Sattelberger, T., Fischer, H. (eds.): Employability Management: Grundlagen, Konzepte, Perspektiven. Gabler, Wiesbaden (2006)

9. Armutat, S., Fassbender, P., Haberkern, K.-H., Kaiser, S., Steinbrücker, U., Szogas, C.: Flexibilitätsorientiertes Personalmanagement: Grundlagen, Handlungshilfen, Praxisbeispiele. W. Bertelsmann, Bielefeld (2006)

10. Bazenski, N., Stowasser, S.: Flexibilität in Unternehmen der Metall- und Elektroindustrie. In: Bornewasser, M., Zülch, G. (eds.): Arbeitszeit - Zeitarbeit: Flexibilisierung der Arbeit als Antwort auf die Globalisierung, pp. 61-76. Springer Gabler, Wiesbaden (2013)

11. Schmidt, D., Hasenau, K., Lehmann, C.: Betriebliche Strategien der Flexibilisierung: die Rolle der Arbeitszeit. In: Bornewasser, M., Zülch, G. (eds.) Arbeitszeit - Zeitarbeit: Flexibilisierung der Arbeit als Antwort auf die Globalisierung, pp. 100-114. Springer Gabler, Wiesbaden (2013)

12. Som, O.: Flexibilität und Stabilität in Betrieben des deutschen Verarbeitenden Gewerbes. In: FraunhoferInstitut für System- und Innovationsforschung (ISI): Flexibilität und Stabilität in Balance - Neue Erkenntnisse zu Einer Vertrauten Verbindung, pp. 15-46. MSK, Köln (2013)

13. Schulte, C.: Personal-Controlling mit Kennzahlen. Vahlen, München (2011)

14. Blum, A., Zaugg, R.J.: Praxishandbuch Arbeitszeitmanagement: Beschäftigung durch innovative Arbeitszeitmodelle. Rüegger, Chur (1999)

15. Kinkel, S., Kleine, O., Maloca, S.: Wandlungsfähigkeit messen und benchmarken. Fraunhofer Institut für System- und Innovationsforschung (ISI), Karlsruhe (2012) 